\title{
INTERVENÇÕES ARTÍSTICAS URBANAS COMO PRÁTICAS CULTURAIS CITADINAS: desobediência à base de tinta na produção de espaços públicos
}

\author{
URBAN ARTISTIC INTERVENTIONS AS A CITIZEN CULTURAL \\ PRACTICES: disobedience based on paint in the production of public
}

spaces

\section{LAS INTERVENCIONES ARTÍSTICAS URBANAS COMO PRÁCTICAS CULTURALES CIUDADANAS: desobediencia basada en la tinta en la producción de espacios públicos}

\section{Valéria Regina Zanetti ${ }^{1}$, Fabiana Felix do Amaral e Silva ${ }^{2}$ \& Bianca Siqueira Martins Domingos ${ }^{3}$}

Resumo: As intervenções artísticas urbanas, para além das cores, ilustrações e tipografias, possuem interfaces com as diferentes formas de apropriação desobediente e subversiva do espaço. O objetivo do artigo centra-se na articulação teórica de conceitos que versam sobre intervenções artísticas urbanas como formas de práticas culturais citadinas que engendram ações sociopolíticas

\footnotetext{
${ }^{1}$ Valéria Regina Zanetti é docente permanente do Programa de Pós-Graduação em Planejamento Urbano e Regional da Universidade do Vale do Paraíba - UNIVAP. vzanetti@univap.br.

${ }^{2}$ Fabiana Felix do Amaral e Silva é docente permanente do Programa de Pós-Graduação em Planejamento Urbano e Regional da Universidade do Vale do Paraíba - UNIVAP. fabiana.amaral@gmail.com.

${ }^{3}$ Bianca Siqueira Martins Domingos é doutoranda no Programa de Pós-Graduação em Planejamento Urbano e Regional da Universidade do Vale do Paraíba - UNIVAP. biancasiqueira.m@gmail.com.
} 
e de desobediências em espaços públicos. No contexto latino-americano, estas práticas demandam a superação da colonialidade, que nos limita na construção de representações sociais e identitárias. Propõe-se apresentar algumas formas de intervenções artísticas urbanas correlacionadas à produção de espaços públicos e entender como as práticas culturais citadinas se inserem nestas dimensões.

Palavras-chave: Espaços públicos; Intervenções artísticas urbanas; Práticas culturais.

\begin{abstract}
Urban artistic interventions, in addition to colors, illustrations and typography, have interfaces with the different forms of disobedient and subversive appropriation of space. The purpose of the article is to focus on the theoretical articulation of concepts that deal with urban artistic interventions as forms of citadinity cultural practices that engender socio-political actions and disobedience in public spaces. In the Latin American context, these practices demand the overcoming of coloniality, which limits us in the construction of social and identity representations. It is proposed to present some forms of urban artistic interventions related to the production of public spaces and to understand how citadinity cultural practices fit into these dimensions.
\end{abstract}

Keywords: Cultural practices; Public spaces; Urban artistic interventions.

Resumen: Las intervenciones artísticas urbanas, además de los colores, las ilustraciones y la tipografía, tienen interfaces con las diferentes formas de apropiación desobediente y subversiva del espacio. El propósito del artículo es centrarse en la articulación teórica de conceptos que abordan las intervenciones artísticas urbanas como formas de prácticas culturales citadinas que engendran acciones sociopolíticas y de desobediencia en el espacio público. En el contexto latinoamericano, estas prácticas demandan la superación de la colonialidad, que nos limita en la construcción de representaciones sociales e identitarias. Se propone presentar algunas formas de intervenciones artísticas urbanas relacionadas con la producción de espacios públicos y comprender cómo las prácticas culturales citadinas encajan en estas dimensiones.

Palabras clave: Espacios públicos; Intervenciones artísticas urbanas; Prácticas culturales.

\title{
1. INTRODUÇÃO
}

Pensar em como a arte e a cultura podem constituir formas de contestação e desobediências em espaços públicos urbanos implica em atravessarmos um amplo repertório de ações protagonizado pelo graffiti, pela pichação e pelas demais intervenções artísticas que constituem processos de fazer e pensar os espaços públicos das cidades. Estas ações, que somam arte e ativismo, se situam sobre a linha tênue que divide o legal do ilegal e o privado do público. Dessa forma, as 
despolíticas, as despoéticas e as desobediências reverberam nos espaços públicos à base de tinta, propondo outras narrativas e lógicas de uso da cidade.

O objetivo do artigo centra-se na articulação teórica de conceitos que versam sobre intervenções artísticas urbanas como formas de práticas culturais citadinas, engendrando ações sociopolíticas e de desobediências em espaços públicos.

Diante da complexa conjuntura sociopolítica e econômica contemporânea brasileira, repensar as ligações entre cultura e poder nos circuitos simbólicos a partir das intervenções artísticas urbanas é um desafio e, sobretudo, uma forma de transcender limites. Multifacetadas, as intervenções artísticas urbanas possuem tramas que alinham cultura popular e arte urbana às formas de se exercer o Direito à Cidade, às vivências citadinas e às ações ligadas a insurgências.

\section{INTERVENÇÕES ARTÍSTICAS URBANAS e produção social do espaço}

Amalgamadas na paisagem da cidade, as artes urbanas, para além do graffiti e da pichação, são instrumentos de resistência que imprimem outras narrativas sobre viver e ocupar as cidades. Ulmer (2017, p. 1, tradução nossa) vislumbra as ruas como "um espaço para o discurso crítico" e "à medida que as tensões entre espaços públicos e privados se desenrolam nas ruas, os artistas de rua reivindicam espaço visível através de múltiplas formas de arte". Romper com os espaços institucionalizados de museus e galerias e levar arte para as ruas é um movimento, sobretudo, de transposição de barreiras sociais, culturais e econômicas.

Uma das principais características das intervenções artísticas urbanas é a espontaneidade e a ausência de regras na elaboração da intervenção na paisagem urbana, desencadeando transformações no tecido da cidade de forma contínua, tornando-se parte que tenciona a lógica instrumental da produção do espaço a partir das narrativas destas expressões culturais (SOUZA, 2012). As transformações urbanas desencadeadas pelas intervenções artísticas impactam na estética, nas políticas/despolíticas e nas poéticas/despoéticas dos espaços públicos, principalmente as não permitidas/não autorizadas. As intervenções artísticas urbanas constituem formas de desobediência civil que, por sua vez, devem ser entendidas a partir da desobediência epistêmica, como forma de livrar a teoria política da economia política eurocêntrica colonizadora (MIGNOLO, 2008). 
Nesta linha epistêmica está implicada a "oferta do pensamento descolonial como a opção dada pelas comunidades que foram privadas de suas "almas" e que revelam ao seu modo de pensar e de saber" (MIGNOLO, 2008, p. 323).

Dentre o amplo repertório de ações desobedientes protagonizado pelas intervenções artísticas urbanas, a expressão "rolê vandal" é utilizada entre os artistas de graffiti quando não há a permissão para a realização da intervenção, muitas vezes valorizada e aplicada à noção de graffiti de verdade. Neste contexto, "vandal" não adquire o significado da tradução direta do inglês (vandalismo), que confere conotação negativa à expressão. $O$ termo enaltece e remete às origens dessas práticas, ao mesmo passo que procura marcar um distanciamento em relação às pinturas comissionadas (LEAL, 2019). No mesmo sentido, o catálogo Cartograffiti, de Mauro Sérgio Neri da Silva (2014, p. 10), traz uma fala do grafiteiro e curador Rui Amaral, que enfatiza: o "graffiti só existe se for livre, sem autorização. Se for autorizado, é arte de rua, arte urbana”.

As intervenções artísticas urbanas alteram as fronteiras entre obra e espectador, aproximando os cidadãos do universo artístico, suscitando subjetividades acerca do que vê. Assim como a arte exposta em museus e galerias, as intervenções artísticas urbanas também trazem consigo a assinatura dos artistas/autores e, ocasionalmente, o ano/data de produção. Essas práticas disruptivas engendram o espaço urbano e alteram a paisagem cotidiana, trazendo à luz as dimensões políticas dos usos da rua "na medida em que constituem práticas de enfrentamento da própria cidade e das normatividades imbricadas no tecido urbano" (LEAL, 2017, p. 43).

Armando Silva (2006) propõe um modelo analítico baseado em sete condições (ou valências) para olhar o graffiti nas cidades, a partir de suas experiências na cidade de Bogotá (Colômbia) nos anos 1980, sendo elas: 1) marginalidade, 2) anonimato, 3) espontaneidade, 4) cenaridade (scenicidad), 5) precariedade, 6) velocidade, e 7) fugacidade. O autor destaca as condições de marginalidade e anonimato como preponderantes na definição do graffiti. De acordo com Silveira (2007, p. 106), "as três primeiras [marginalidade, anonimato e espontaneidade] são pré-operativas, isto é, antecedem o próprio registro. [...]”. O último elemento, a fugacidade, "seria uma valência pós-operativa, pois se refere à consideração das instâncias de controle e censura (policiamento e limpeza, por exemplo) das expressões mais originais". 
Há também três possibilidades de interpretações que envolvem funções enunciativas e narrativas, nas quais Silva (2014) chama de operações de modo progressivo: 1) O objeto de exibição; 2) Observação por um sujeito; e 3) Olhar citadino.

$\mathrm{Na}$ disputa dialética entre a dimensão pública e a privada na ocupação urbana, as transformações que ocorrem em uma impactam concomitantemente a outra, em que o antagonismo entre ambos deve ser substituído por uma relação de complementariedade (CORTES, 2008). A democratização do uso dos espaços urbanos, a efervescência dos movimentos sociais e as novas formas de urbanização estão presentes no modus operandi das intervenções artísticas urbanas. $\mathrm{O}$ artista de graffiti/grafiteiro se apropria do espaço para se expressar por meio da arte ao público, coletivizando sua ação. O graffiti é, sobretudo, a subversão do uso do espaço público planejado e se constitui não só no pensamento descolonial como também o fazer descolonial ao propor contrapontos às gestões neoliberais e excludentes.

A gestão de João Doria na Prefeitura de São Paulo (2017 - 2020) traz um exemplo que evidencia as lógicas neoliberais centradas na dimensão da cultura, em que a cobertura/apagamento de graffitis e pichações "com tinta cinza se espalharam por toda a cidade em 2017 sob a denominação de "Operação Cidade Linda" (alguns graffitis apagados pessoalmente pelo prefeito)" (DOMINGOS, ELOY E FERNANDES, 2017, p. 17), Figuras 1 (a) e (b). Acompanhando esta operação, foi anunciada a intenção de criar o "Museu de Arte de Rua" (MAR), com o objetivo de monetização e inspirado em um espaço de cultura e comércio de Miami, que não foi posta em prática na gestão. Sem consulta à opinião citadina sobre a "Operação Cidade Linda", o sentido de participação ativa na esfera pública foi suprimido e silenciado.

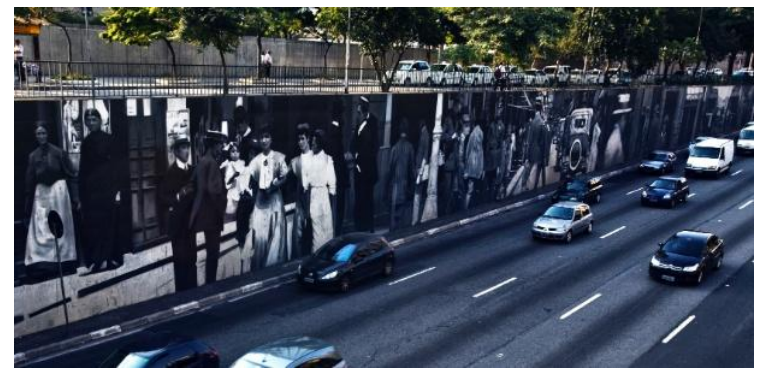

(A)

Cadernos de estudos culturais, Campo Grande, MS, v. 2, p. 227-241, jul./dez. 2020. 


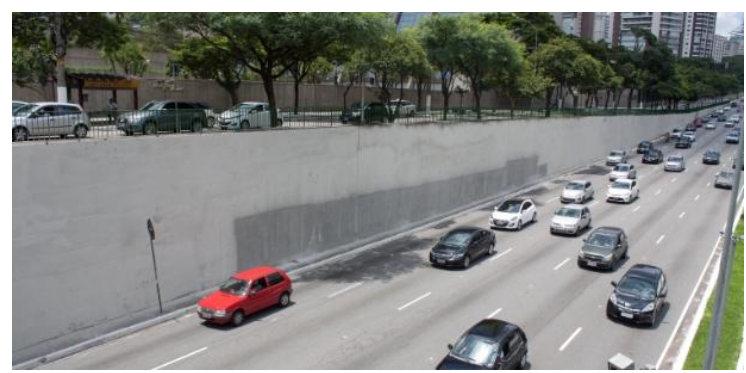

(B)

FIGURAS 1 (A) E (B) - (a) graffiti de Eduardo Kobra na Av. 23 de maio e (b) graffiti apagado pela "Operação Cidade Linda".

FONTE: UOL (2017).

Esse recorte empírico expressa o importante papel do pensamento descolonial nas ações de citadinidade frente aos apagamentos e silenciamentos às expressões e narrativas urbanas advindas das intervenções artísticas, como no caso da "Operação Cidade Linda". A descolonialidade coloca em prática, por meio do questionamento, da crítica e de ações de desobediências, as lógicas neoliberais de construção simbólica e material da esfera pública.

Para Arendt (1958, apud Bhabha,1998, p. 35), um dos sentidos da esfera pública se interliga ao compartilhamento, à identificação de pontos de conexão que existem entre pessoas. O termo público nos alude ao fato de "tudo o que aparece em público poder ser visto e escutado por todos", sendo este fenômeno relacionado ao nosso sentimento e sentido de realidade. "Na presença de outros, que veem o que nós vemos e ouvem o que nós ouvimos", está a "condição para compreender a realidade do mundo e de nosso próprio Eu" (BHABHA, 1998, p. 35). Nessas conexões entre as pessoas e os espaços públicos, o privado e o público, o passado e o presente, "o psíquico e o social desenvolvem uma intimidade intersticial” (BHABHA, 1998, p. 35).

As intervenções artísticas urbanas visuais ganham forma em construções privadas e públicas por meio de estêncil (forma vazada por meio da qual é usado o spray de tinta), projeções de vídeos ou imagens, colagens (lambe-lambe ou adesivos), bomb (graffiti rápido), grapixo (híbrido das duas técnicas) (FILARDO, 2015). 
Benke (2015) inclui na lista de intervenções artísticas urbanas pôsteres, adbusting $^{4}$, jardinagem de guerrilha ${ }^{5}$, mosaicos, adesivos, instalações, serigrafia e perler beads ${ }^{6}$. O autor destaca o graffiti e a pichação como as principais ferramentas de intervenções, ressaltando que os artistas sempre trabalham in loco e geralmente à mão livre, diretamente sobre a superfície (parede ou asfalto). Cada artista de rua possui um estilo próprio de "cores, traços e sombras, pelo qual também serão reconhecidos e dimensões podem alterar-se ao longo de suas trajetórias à medida que ampliam seus repertórios de possibilidades estéticas" (LEAL, 2019, p. 100), que são acompanhadas de assinaturas (tag) de autoria.

O enunciado "Graffiti é sobre fazer isso, ser isso e pintar isso" (POWERS, 1999 apud LEAL, 2019, p. 91) nos abrem perspectivas para o fato de que "graffiti não é só tinta no muro". A mais conhecida das intervenções artísticas urbanas visuais possui práticas que nos remetem ao início da humanidade com um desejo que se mantém até hoje: o de deixar marcas nos espaços.

O graffiti, "enquanto forma de expressão social urbana" propicia "formas de expressão que caracterizam e se tornam formas de linguagem de indivíduos dentro de seu meio social e de seu tempo" (FURTADO E ZANELLA, 2009, p. 10). Para Bissoli (2011, p. 19), o graffiti "captura olhares na cidade, comunica, evidencia muros, restos, abandonos, o novo, o velho, pequenos e grandes objetos, pedaços e inteiros. Institui uma nova ordem, uma outra cidade, outro território, outra paisagem", evidenciados nas dimensões das ações sócio-políticas. Quando estas expressões sociais urbanas se descolonializam, novas leituras fora dos conceitos políticos que racializaram a geografia do conhecimento ganham contornos a partir de epistemologias que se desvinculam de "fundamentos genuínos dos conceitos ocidentais e da acumulação de conhecimento", ressalvando que, ao se referir ao

\footnotetext{
4 “Também chamado de subvertising, é uma corrente de arte urbana que busca conseguir nossa atenção alterando as mensagens de publicidade presentes nas cidades” (BENKE, 2015, p. 29).

${ }^{5}$ Os jardineiros de guerrilha costumam usar áreas esquecidas ou mal usadas nas cidades, questionando a forma como a cidade é planejada e cultivada (BENKE, 2015). Essa intervenção parece ser bem interessante pra discutir a opção descolonial e o fazer descolonial proposto por Mignolo.

${ }^{6}$ Uso de miçangas ou tubos plásticos derretidos para composição de figuras ou ilustrações (BENKE, 2015).
} 
ocidente, considera-se a dimensão "geopolítica do conhecimento" (MIGNOLO, 2008, p. 290).

A opção descolonial demanda desobediências epistêmicas e "uma ampla e global orientação descolonial (com inclinação) de pensar e de agir", em que a cultura, por meio das expressões sociais urbanas, desempenham importantes papéis estéticos de reafirmação identitária (MIGNOLO, 2008, p. 323).

Frequentemente o graffiti é contraposto à pichação, "em que o primeiro se caracteriza por um tipo de intervenção geralmente não autorizada, porém com uma maior preocupação estética em relação à pichação" e, o graffiti, se diferencia por utilizar multicores em detrimento da pichação, geralmente monocromática e fruto de preconceito social (DOMINGOS, ELOY e FERNANDES, 2017, p. 3). Pereira (2010, p. 107) destaca que, apesar de possuir dinâmicas próprias na cidade, "pixadores e grafiteiros circulam por um mesmo circuito na cidade: o das artes de rua. Por isso, as relações entre os adeptos das duas expressões visuais são marcadas por aproximações e distanciamentos. Há, inclusive, muitos que são adeptos das duas atividades".

Gitahy $(1999$, p. 24) enfatiza que a pichação "é uma guerra feita com tinta, todos se conhecem e se identificam pelo tipo de código pichado. Um grande abaixo-assinado para a posteridade, no qual cada um que participa deixa sua marca". (...) "A pichação aparece como uma das formas mais suaves de dar vazão ao descontentamento e à falta de expectativas". Na relação entre artistas de rua versus regulamentações, o fato desses artistas serem vistos como "foras da lei" está longe de ser um problema, em que "o desdém pela lei é visto como parte do apelo desse gênero".

As diversas formas de intervenções artísticas urbanas são práticas culturais que politizam o cotidiano a partir de ações sociopolíticas citadinas à base de tinta. As intervenções trazem no seu ethos práticas de enfrentamento, de descolonialidade, de despolíticas, despoéticas e desobediências às normatividades imbricadas no tecido urbano, produzindo espaços públicos a partir de outras narrativas.

\section{OS ELOS QUE UNEM PRÁTICAS CULTURAIS à Citadinidade}


O conceito de citadinidade se constrói a partir de exercícios situacionais, por meio de ativismos, do uso lúdico da cidade e da apropriação do espaço urbano que preza pelas vivências e agenciamentos. Esse conceito trata dos movimentos de resistência que fazem a cidade de forma criativa por meio das práticas culturais citadinas como o graffiti, skate, saraus e outros. O exercício da citadinidade envolve táticas, criatividades e astúcias, desencadeando o uso ampliado dos espaços urbanos.

A citadinidade se refere "às práticas e representações de indivíduos e grupos, entendidos como atores sociais". Pode ser definida também como uma relação dinâmica entre um ator individual (ou coletivo) e o objeto urbano. Essa noção surgiu na década de 1990 em estudos baseados nas práticas e representações dos habitantes (BERRY-CHIKHAOUI, 2009, p. 10, tradução nossa).

Para alguns, acentua Berry-Chikhaoui (2009), a "cidade e urbanidade podem ter o mesmo significado, para outros, significados semelhantes e, para outros ainda, referem-se a significados diferentes" (BERRY-CHIKHAOUI, 2009, p. 11, tradução nossa). Porém, a distinção entre essas categorias pode ser feita a partir da significação de que a urbanidade versa sobre as potencialidades em termos de vínculo social e, a citadinidade, versa (e questiona) a dimensão espacial da construção de práticas e representações sociais (BERRY-CHIKHAOUI, 2009, p. 11, tradução nossa). A autora francesa traz mais pontos a serem considerados na distinção entre essas categorias, incluindo a categoria de cidadania:

Citadinidade refere-se a modos de viver e à construção de identidades, e urbanidade às dimensões materiais e simbólicas do espaço, às qualidades que o definem como urbano (incluindo e especialmente nas representações sociais). Quanto à cidadania, para além de uma definição estritamente política ou jurídica em termos de status, direitos e deveres, antes se referia a formas de engajamento, busca de reconhecimento, reivindicações e manifestação, em e para o espaço, muitas vezes no sentido de maior justiça espacial (BERRY-CHIKHAOUI, 2009, p. 13, tradução nossa).

O conceito de citadinidade versa sobre uma cidadania que não se reduz ao ato de votar ou pagar impostos, mas sim a uma cidadania de participação ativa nos processos democráticos e de transformações urbanas. Repensar criticamente as práticas citadinas ligadas à cultura no contexto latino-americano implica em superarmos a colonialidade do saber, do ser e do poder, na qual os colonizadores nos forçaram "a aprender parcialmente a cultura dos dominadores em tudo que 
fosse útil para a reprodução da dominação, seja no campo da atividade material, tecnológica, como da subjetiva, especialmente religiosa" (QUIJANO, 2005, p. 111).

Considerar a junção do conceito de citadinidade às práticas culturais na realidade latino-americana implica em compreender que as expressões do graffiti e da pichação trazem outras dimensões que perpassam a concepção de uma democracia frágil, com estruturas de controle e poder baseados no contrato da violência, da exclusão e do racismo. Muitos movimentos sociais situados na América Latina buscam revelar e incorporar à citadinidade o direito de poder falar e legitimar suas próprias percepções sobre a cidade e seus grupos.

Ampliando esses conceitos sob a perspectiva de novas relações do sujeito com o espaço urbano, o graffiti e a pichação latino-americanos possuem narrativas discursivas que performam como insurgências, ainda que sob a égide das dimensões do controle, dos pactos em localidades e experiências de democracias frágeis.

As relações dos citadinos com o espaço urbano podem alterar dependendo de cada implicação situacional (engagement situationnel), que possui quatro tipos de situações. São elas: a) situação ordinária (situações regulares, diárias, hábitos, costumes e práticas corriqueiras); b) ocasional ou extraordinária (situações acidentais, raras ou imprevistas); c) situação de passagem (atravessar não lugares como no trânsito, hotéis, avião, ruas, rodovias, aeroportos) e; d) situação ritual (festas, danças, carnaval, ritos religiosos) (AGIER, 2015). A Figura 2 traz o diagrama das situações da vida cotidiana, que ilustra, por meio das relações entre indivíduo, espaço e sociedade, quais são as relações principais e as secundárias diante de cada implicação situacional.

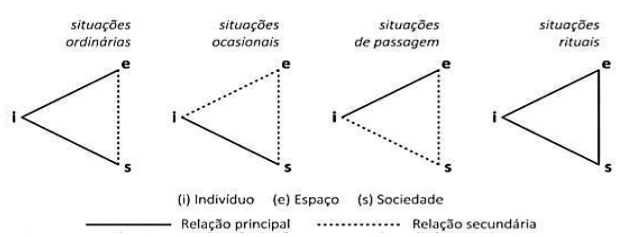

FIGURA 2 - Diagrama das Situações da Vida Cotidiana

FONTE: adaptado de Agier (2015, p. 92)

No caso das situações ordinárias, a ênfase na relação principal está entre indivíduo e espaço e indivíduo e sociedade. Nas situações ocasionais, a ênfase na 
relação principal está entre indivíduo e sociedade. No caso das situações de passagem, a ênfase está na relação principal entre indivíduo e espaço e, nas relações rituais, a relação principal triangulada entre indivíduo, espaço e sociedade (AGIER, 2015).

O graffiti pode ser enquadrado em dois tipos de implicações situacionais: a) situações rituais: dada a intensa relação do autor da intervenção (indivíduo) com o espaço e a sociedade ao passo que o artista de graffiti imprime sua marca no espaço urbano e deixa uma mensagem à sociedade (ilustrada ou tipográfica, abstrata ou com significado expresso, colorida ou monocromática); b) situações ocasionais: quando o graffiti é realizado de forma ilegal ou irregular, podendo ocorrer prisões, aplicação de multas e/ou apreensões.

Ao examinar as potencialidades dos lugares públicos em portar as expressões culturais, Agier (2015, p. 143) propõe dois grandes domínios de criação que compõe a cultura da cidade: a primeira "diz respeito às relações entre citadinos, ou seja, às representações da identidade e da alteridade" e, a segunda, "é simbólica com que os habitantes dão um sentido ao espaço material da cidade onde vivem".

Partindo de um ponto de vista social, político e cultural, a cidade está em constante e plena construção, em processo, em disputa e em co-existência (AGIER, 2015, p. 484). Certeau (1994) propõe um enveredamento por outros caminhos, que analisam as "práticas microbianas, singulares e plurais", como seguir o pulular dos procedimentos que escapam à administração panóptica e das redes de vigilância, que "constituem regulações cotidianas e criatividades subreptícias que se ocultam somente graças aos dispositivos e aos discursos, hoje atravancados, da organização observadora" (p. 175). O graffiti e as intervenções artísticas urbanas perpassam por estas práticas descritas por Certeau (1994) e dialogam com Mignolo (2008) ao se desvincularem epistemicamente dos conceitos racialistas ocidentais e de acumulação de conhecimento georreferenciados, pois "toda mudança de descolonização política (não-racistas, não heterossexualmente patriarcal) deve suscitar uma desobediência política e epistêmica" (MIGNOLO, 2008, p 287).

Inseridas nas práticas de intervenções artísticas urbanas, a crítica sociopolítica é um importante elemento reivindicatório que compõe as narrativas dos artistas, grafiteiros e pichadores. Desta forma, a opção descolonial encontra na identidade em política o ponto crucial, uma vez que, sem a "construção de teorias 
políticas e a organização de ações políticas fundamentadas em identidades que foram alocadas [...] por discursos imperiais [...] pode não ser possível desnaturalizar a construção racial e imperial da identidade no mundo moderno em uma economia capitalista" (MIGNOLO, 2008, p. 289).

Especificamente sobre os elos do graffiti com a citadinidade, Leal (2019, p, 90), ao "descrever e refletir sobre os efeitos que estas práticas produzem nos sujeitos que pintam na rua", demonstra que essas práticas e experiências engendram formas de citadinidade. Aproximando-nos de Certeau (1994, p. 105), as práticas de graffiti revelam "maneiras de pensar investidas em maneiras de fazer". Silva (2014, p. 103) aborda o olhar citadino sobre o graffii como "um exercício coletivo de base ética e estética que, é claro, filtra e seleciona todo acontecer social posto em circulação pública, que pode chamar grafite ou não. No entanto, é neste ponto que talvez possamos estabelecer uma ponte muito precisa entre enunciação e leitura individual e coletiva".

Portanto, o graffiti emerge como um mecanismo de conexão e associação que existem contra o vazio de sentido dos espaços urbanos, tornando a cidade um "dispositivo cultural" (AGIER, 2015, p. 170). A rua "torna-se o espaço da política e da invenção cultural", perfazendo a dimensão da cultura das cidades (p. 182).

\section{CONSIDERAÇÕES finais}

Conclui-se que as diversas formas de intervenções artísticas urbanas, por meio das práticas culturais citadinas, propõem desobediências na produção de espaços públicos em implicações situacionais rituais e ocasionais, de acordo com Agier (2015).

A opção pela descolonização do conhecimento que atravessa as práticas das intervenções artísticas urbanas endossa um importante posicionamento contra a desqualificação do discurso político das cores, nas diferentes dimensões que o termo cores suscita. Por meio de ilustrações, tipografias e de diversos tipos de intervenções, nossas identidades são resgatadas, reafirmadas e postas em destaque em espaços públicos, reagindo contra os silenciamentos que o colonialismo traz. Neste contexto, as críticas sociopolíticas e as desobediências possuem papel fundamental. 
A quebra epistêmica descolonial à base de tinta em espaços públicos propõe múltiplas construções de representações sociais e identitárias, e as práticas culturais citadinas propiciam uma participação ativa nos processos democráticos e de transformações urbanas.

\section{AGRADECIMENTOS}

Os autores agradecem à Coordenação de Aperfeiçoamento de Pessoal de Nível Superior (CAPES) pela bolsa de doutorado.

\section{REFERÊNCIAS}

AGIER, M. Do Direito à Cidade ao Fazer-Cidade. O Antropólogo, a Margem e o Centro. Mana, Rio de Janeiro, v. 21, n. 3, p. 483-498, Dec. 2015. Disponível em: $<$ http://www.scielo.br/scielo.php?script=sci_arttext\&pid=S010493132015000300483\&lng=en\&nrm=iso>. Acesso em 13 de ag. de 2020.

BENKE, C. Street art: técnicas e materiais para arte urbana: grafite, pôsteres, adbusting, estêncil, jardinagem de guerrilha, mosaicos, adesivos, instalações, serigrafia, perler beads. 1 ed. São Paulo: Gustavo Gili, 2015.

BERRY-CHIKHAOUI, I. Les notions de citadinité et d'urbanité dans l'analyse des villes du Monde arabe. Les Cahiers d'EMAM [En ligne], 18 | 2009, Disponível em: <http://journals.openedition.org/emam/175>. Acesso em 13 de agosto de 2020.

BHABHA, H. O local da cultura. Belo Horizonte: Editora UFMG, 1998.

BISSOLI, D. C. Graffiti: paisagem urbana marginal. A inserção do graffiti na paisagem urbana de Vitória (ES). 2011. 218 f. Dissertação (Mestrado) - Arquitetura e Urbanismo, Universidade Federal do Espírito Santo, Vitória, 2011.

CERTEAU, M. A Invenção do Cotidiano. Petrópolis, RJ: Vozes, 1994.

CORTÉS, J. M. G. Políticas do espaço: arquitetura, gênero e controle social. São Paulo: Editora Senac São Paulo, 2008.

DOMINGOS, B. S. M.; ELOY, G. O.; FERNANDES, L. F. V. M. Concretos que falam: análise comparativa de grafites sob vias suspensas nas cidades de São Paulo e Lorena/SP. Ponto Urbe [Online], $20 \quad$ 2017. Disponível em: $<$ http://journals.openedition.org/pontourbe/3426>. Acesso em 29 de mar. de 2020. 
FILARDO, P. R. Pichação (pixo). Histórico (tags), práticas e a paisagem urbana. Arquitextos, São Paulo, ano 16, n. 187, Vitruvius, dez. 2015 Disponível em: http://www.vitruvius.com.br/revistas/read/arquitextos/16.187/5881. Acesso em 29 de mar.de 2020.

FLESSAS, T.; MULCAHY, L. Limiting law: Art in the street and street in the art. Law, Culture and the Humanities, 14(2), 2018, p. 219-241.

FURTADO, J. R; ZANELLA, A. V. Graffiti e cidade: sentidos da intervenção urbana e o processo de constituição dos sujeitos. Revista Mal-estar e Subjetividade, Fortaleza, n. 4, dez. 2009. p.1279-1302,

GITAHY, C. O que é Graffiti. São Paulo: Editora Brasiliense, 1991.

LEAL, G. P. O. "Graffiti é existência": reflexões sobre uma forma de citadinidade. Horiz. antropol., Porto Alegre, v. 25, n. 55, p. 89-117, dez. 2019. Disponível em: $<$ http://www.scielo.br/scielo.php?script=sci_arttext\&pid=S0104-

$71832019000300089 \& \operatorname{lng}=p t \& n r m=i$ so $>$. Acesso em 28 de jun. de 2020.

. Graffiti para além dos muros: Usos da rua e práticas de enfrentamento da cidade. Enfoques, Vol. 16, nº 1, pp. 32-44, 2017.

MIGNOLO, W. D. Desobediência epistêmica: a opção descolonial e o significado de identidade em política. Cadernos de Letras da UFF. Dossiê: Literatura, língua e identidade. n. 34, 2008, pp. 287-324.

PEREIRA, A. B. As marcas da cidade: a dinâmica da pixação em São Paulo. Lua Nova, São Paulo, n. 79, p. 143-162, 2010. Disponível em: http://www.scielo.br/scielo.php?script=sci_arttext\&pid=S010264452010000100007\&lng=en\&nrm=iso. Acesso em 29 de mar. de 2020.

QUIJANO, A. Colonialidade do Poder, Eurocentrismo e América Latina. Em: LANDER, Edgardo (Org). A colonialidade do saber: eurocentrismo e ciências sociais. Perspectivas latinoamericanas. Colección Sur Sur. Ciudad Autónoma de Buenos Aires, Argentina: CLACSO, 2005a. p. 107-129.

SILVA, A. Imaginarios urbanos. Bogotá y Sao Paulo: cultura y comunicación urbana en América Latina. $5^{\text {a }}$ ed. Bogotá: Tecer Mundos Editores, 2006.

Atmosferas urbanas: grafite, arte pública, nichos estéticos. Tradução de Sandra Trabucco Valenzuela. - São Paulo: Edições Sesc São Paulo, 2014.

SILVA, M. S. N. S. Cartograffiti. São Paulo: Prefeitura de São Paulo, 2014.

SILVEIRA, F. Remediação e extensões tecnológicas do grafite. Revista Galáxia, São Paulo, n. 14, , dez. 2007, p. 95-109. 
SOUZA, L. F. Intervenção urbana na cidade pós-moderna: Rua Trajano Reis em Curitiba. 2012. Monografia (Pós-Graduação) Comunicação, Cultura e Arte da Pontifícia. Universidade Católica do Paraná, 2012.

ULMER, J. B. Writing Urban Space: Street Art, Democracy, and Photographic Cartography. Cultural Studies - Critical Methodologies, 17(6), 2017, p. 491-502.

Artigo recebido em: 29 de setembro de 2020. Artigo Aprovado em: 13 de dezembro de 2020. 
